\title{
Verwendete Marginalien
}

Zur besseren Übersicht werden im Buch unterschiedliche Symbole als Marginalien verwendet. Sie haben die folgenden Bedeutungen:

Definition:

Hier werden zentrale Begriffe definiert und in ihrer Verwendung in diesem Buch bestimmt.

Tipps \& Tricks:

Tipps, Hintergrundinformationen aber auch Warnungen finden Sie hier.
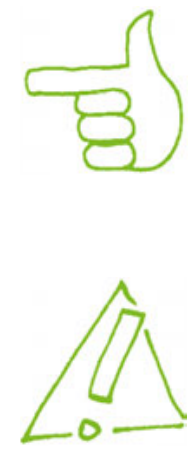

Achtung:

Zusammenfassungen und wichtige Aufzählungen sind mit diesem Symbol gekennzeichnet.

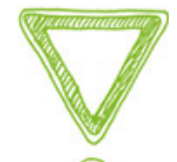

(0)

Praxisaufgaben:

Kleine Aufgaben helfen Ihnen das Gelesene in die eigene Arbeitspraxis zu übertragen.

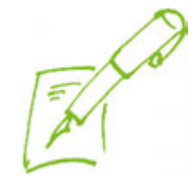


